\title{
Insights into the misfolding of $\alpha$-synuclein in the presence of metal ions: a simulation study
}

\begin{abstract}
Molecular dynamics of $\alpha$-synuclein in the presence of five different salt concentrations show that $\mathrm{Zn}^{2+}$ enhanced the stability of the protein monomer while $\mathrm{K}^{+}$shows opposite effect. Higher regions of $\alpha$-synuclein unfolding was seen between the residues 100-140 in the presence of $\mathrm{NaCl}$ and $\mathrm{KCl}$ while the presence of $\mathrm{CaCl}_{2}$ and $\mathrm{MgCl}_{2}$ results in similar unfolding between the residues $60-80$. In contrast, the unfolding of $\alpha$-synuclein in the presence of $\mathrm{ZnCl}_{2}$ deviate from other salts indicating the influence of $\mathrm{Zn}^{2+}$ in the unfolding of the secondary and tertiary structures of $\alpha$-synuclein. In protein dimers, these misfolding of $\alpha$-synuclein are commonly seen between the residues $80-100$ in all these five salts indicating that the NAC region of the dimer is mainly involved in protein unfolding. Mutation of Ala30Pro clearly shows that decreased the stability of $\alpha$-synuclein monomer while $\mathrm{Ca}^{2+}$ influenced protein aggregation in protein dimer. Removing the residues from $110-140$ reduced the stability of monomer in the presence of $\mathrm{K}^{+}$while shows higher stability with $\mathrm{Ca}^{2+}$ in the protein dimer. However, both $\mathrm{Na}^{+}$and Miens show variations in different forms of the protein. These results show that $\alpha$-synuclein is less prone to aggregation in the presence of $\mathrm{Zn}^{2+}$ which may have implications for the prevention and therapeutics of the Parkinson's disease.
\end{abstract}

Keywords: $\alpha-$ synuclein, simulations, fibrillization, circular dichroism, oligomerization
Volume 2 Issue 2 - 2018

\author{
Nataraj Sekhar Pagadala \\ Department of elecrical and computer engineering, University \\ of Alberta, Canada
}

Correspondence: Nataraj Sekhar Pagadala, Department of elecrical and computer engineering, University of Alberta, Canada,Email nattu25।@gmail.com

Received: April 03, 2018 | Published: April 18, 2018

\section{Introduction}

Parkinson's disease is a degenerative neurological disease of the central nervous system characterized by rigidity, tremors, and bradykinesia. It is the most common form of age-cognate neurodegenerative disorder after Alzheimer's that is associated in formation of amyloid-like fibrils at neuronal surfaces. ${ }^{1,2}$ This is caused by the loss of dopaminergic neurons in the brain. A molecular hallmark of $\mathrm{PD}$ is the accumulation of protein aggregates called as Lewy bodies that play an important role in neuronal loss. A major component of these aggregates is the natively unfolded for of the protein $\alpha$-synuclein in solution. The disease is also linked with two mutations (A30P and A53T) which seem to endow $\alpha$-synuclein with a higher propensity to form aggregates in the substantia nigra. ${ }^{3}$ Fibrillization of $\alpha$-synuclein is the major component of Lewy bodies (LBs) and Lewy neuritis (LNs) that leads to the pathogenesis of the disease. ${ }^{4,5}$ Since these amyloid fibrils are highly insoluble and non-crystalline, the details of protein aggregation at the atomic level are still difficult to obtain. ${ }^{6,7}$ Circular dichroism (CD) and other optical methods reveal that $\alpha$-synuclein is highly unstructured and is very sensitive to environmental conditions such as $\mathrm{pH}$, temperature, density, presence of metal ions, micelles, and lipid bi-layer membranes. ${ }^{8-13}$ NMR studies and sequence similarities have shown the detailed structure and dynamics of micelle-bound $\alpha-$ synuclein in solution adopting a helical structure. ${ }^{14-18}$ The $140-$ amino acid sequence of $\alpha$-synuclein is divided into three regions: $N$-terminal, central and C-terminal. ${ }^{19,20}$ In vitro and cell-based assays have shown diminished $\alpha$-synuclein oligomerization and fibrillogenesis when large segments within this motif are deleted..$^{21-23}$ Experimental studies also revealed three critical point mutations in the $\alpha$-synuclein gene: A53T, A30P, and E46K. ${ }^{24-26}$ However, NMR spectroscopy revealed that mutation of A30P strongly attenuated the helical propensity found in the $\mathrm{N}$-terminal region of wild type $\alpha$-synuclein. ${ }^{27}$ The A30P mutation promoted $\alpha$-synuclein oligomer formation by introducing a kink on the second helix, which may impact its folding and/or normal function, while the A53T and E46K mutations promote fibrillation Highly conserved residues are indicated in red and variable sequences are indicated in yellow. Residues from 1-60 are indicated in black color box, 61-95 are indicated in violet color box and 96-140 are indicated in orange color box Figure 1. Previous simulations using the micelle-bound NMR structure revealed the formation of $\alpha$-synuclein dimers, pentamers and hexamers in a ring like form. ${ }^{28}$ Truncated $\alpha-$ synuclein (residues 1-95) when bound to planar bilayers allows the protein to form a bent helix, with the largest bend around residue 47 due to the collective motions of the long helix. Computational methods also predicted the structure of the N-terminal domain of $\alpha$-synuclein. ${ }^{29}$ Molecular Dynamics (MD) simulations of the NAC peptide using the replica exchange method under various conditions revealed that each individual conformation is highly flexible close to a random coil. However, simulations of the intermolecular beta sheets located between the residues 71-82 indicate that anti-parallel betasheet conformers are stable at and above the $320 \mathrm{~K}$ temperature. MD simulations also suggest that monomeric mutant forms of $\alpha$-synuclein in disease state do not show higher propensities for extended beta conformations than wild-type $\alpha$-synuclein. Inter-residue separation of monomeric $\alpha$-synuclein was measured at neutral and low $\mathrm{pH}$ ensembles using the single-molecule fluorescence resonance energy transfer (sm FRET) method. ${ }^{30,31}$ These inter-residue separations implemented in Monte Carlo simulations as constraints investigate the natively disordered ensemble of conformations using geometry (e.g., Bond length and bond angle) and repulsive Lennard-Jones interactions. Conformational dynamics at $293 \mathrm{~K}$ at neutral $\mathrm{pH}$ using all-atom, united-atom, and coarse-grained methods show that the structure of $\alpha$-synuclein is intermediate between that for random walks and collapsed globules. ${ }^{32}$ Simulation studies at higher temperatures showed that fibril formation of $\alpha$-synuclein was substantially inhibited due to $\mathrm{C}$-terminal truncation and oligomer formation rather than conformation changes of the monomeric residues. ${ }^{33}$ Despite these significant recent advances, the mechanism of $\alpha$-synuclein 
aggregation and toxicity is still not understood in detail. In this study, the experimentally-determined micelle-bound structure of $\alpha-$ synuclein (PDB code 1XQ8) consisting of two alpha helices linked by a long loop of 8 residues was downloaded from the Protein Data Bank Figure 2. The ion-specific behavior of monovalent and divalent metal ions $\mathrm{Na}^{+}, \mathrm{K}^{+}, \mathrm{Ca}^{2+}$, Mand $\mathrm{Zn}^{2+}$ was investigated by means of extensive MD simulations of $\alpha$-synuclein in aqueous salt solutions. Earlier studies have reported that unfolding and aggregation of $\alpha$-synuclein differs in different salts, such as $\mathrm{NaCl}, \mathrm{KCl}, \mathrm{MgCl}_{2}, \mathrm{CaCl}_{2}$ and $\mathrm{ZnCl}_{2}$ at the same ionic concentration giving rise to its partial folding to the amyloidogenic conformation. To gain insights into the first steps of alpha-synuclein unfolding and aggregation, MD simulations for alpha synuclein monomer and dimer were performed in the presence of water and in different salt concentrations at physiological $\mathrm{pH}$ using the OPLS force field with explicit water.
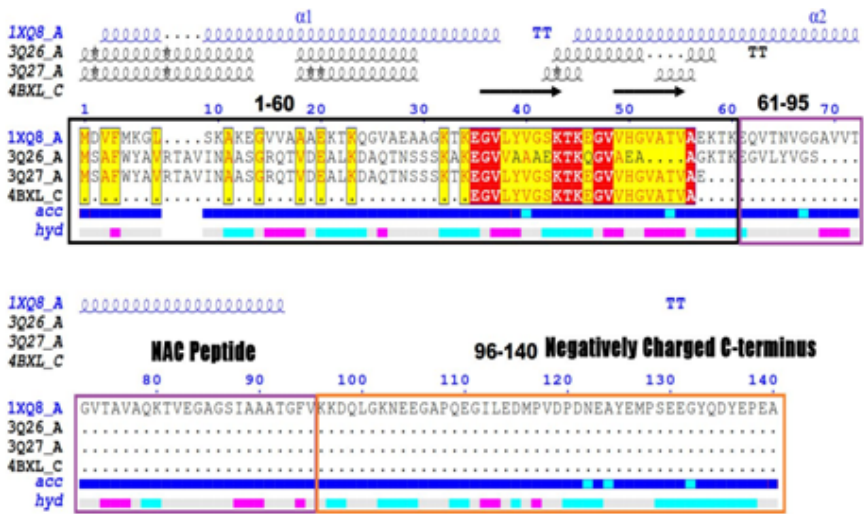

Figure I Scheme of $\alpha$-synuclein primary structure
A

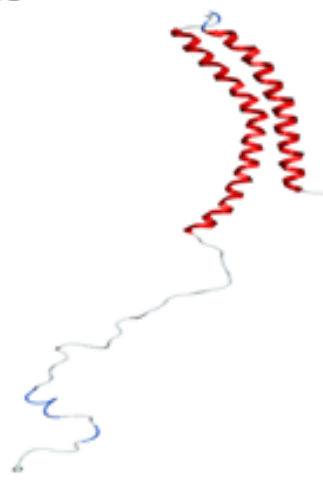

B

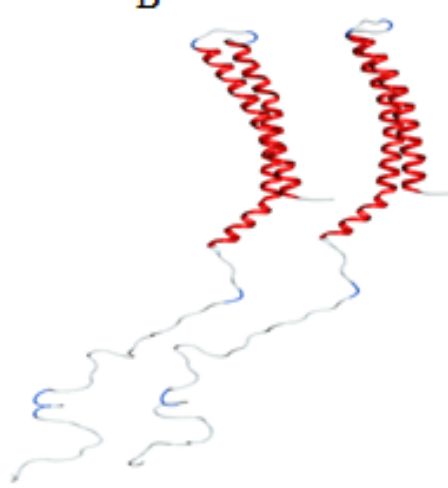

Figure 2 Initial structures of human $\alpha$-synuclein monomer $(A)$ and dimer (B)

\section{Methodology}

The structure of $\alpha$-synuclein monomer was obtained from a Protein data bank (PDB:1XQ8) and its dimer was constructed using HEX protein docking software both forms of the protein were simulated by molecular dynamics and calibration methods with NAMD 2.5 software using the OPLS force field, along with the TIP3P model for explicit water at physiological $\mathrm{pH}$. The simulations began with a 1000 -step minimization to remove any bad contacts between the designed side chains and solvent. A cut-off of $12 \AA$ (switching function starting at $10 \AA$ ) for vander Waals interactions was assumed. An integration time- step of $2 \mathrm{fs}$ was used, permitting a multiple time-stepping algorithm to be employed, in which interactions involving covalent bonds were computed every time step. Short-range non-bonded interactions were computed every two time-step, and long-range electrostatic forces were computed every four time-steps. The pair list of the nonbonded interactions was recalculated every ten time-step with a pair list distance from $13.5 \AA$. The short-range non-bonded interactions were defined as vander Waals and electrostatic interactions between particles within $12 \AA$. A smoothing function was employed for the vander Waals interactions at a distance of $10 \AA$. The backbone atoms were harmonically constrained with a restraining constant of $10 \mathrm{k} \mathrm{cal} /$ mol $\AA^{2}$, and the systems were heated to $310 \mathrm{~K}$ over the course of $6 \mathrm{ps}$ at constant volume. The simulations were equilibrated for $2 \mathrm{~ns}$ with NVT ensemble (1atm, $310 \mathrm{~K}$ ) while the harmonic constraints were gradually turned off. With no harmonic constraints, the simulations ran for $50 \mathrm{~ns}$ in the NVT ensemble using Langevin dynamics at a temperature of $310 \mathrm{~K}$ with a damping coefficient of $\gamma=5 \mathrm{ps}^{-1}$. Pressure was maintained at $1 \mathrm{~atm}$ using the Langevin piston method with a piston period of $100 \mathrm{fs}$, a damping time constant of $50 \mathrm{fs}$ and a piston temperature of $310 \mathrm{~K}$. Non-bonded interactions were smoothly switched off from 10 to $12 \AA$. The list of non-bonded interactions was truncated at $14 \AA$. Covalent bonds involving hydrogen were held rigid using the Shake algorithm, allowing a 2-fs time-step. No periodic boundary conditions were included in the above studies. Atomic coordinates were saved every $1 \mathrm{ps}$ for the trajectory analysis.

\section{Results}

\section{MD simulations in the presence of $\mathrm{NaCl}$}

In the presence of $\mathrm{NaCl}$, the negatively-charged $\mathrm{Cl}^{-}$ions are attracted by the positively-charged free amino groups with lysine's located in the helices -1 and 2 of $\alpha$-synuclein. These interactions destabilize the folded protein to unfold into four shorter helices from Figure 3A. However, the stability of these helices is not much affected in a protein dimer because of strong intermolecular interactions within the protein monomers in both $\mathrm{N}-$ and $\mathrm{C}$-terminal regions Figure 3B. This shows that sodium ions play a predominant role in keeping the protein dimer intact compared to protein monomers. With Ala30Pro mutant, the chloride ions don't show any contacts with the protein residues. Out of $22 \mathrm{Na}^{+}$only 7 ions show interaction with the negatively-charged residues in the $\mathrm{N}$-terminal region of the protein. These fewer interactions of sodium ions unfold helices -1 and 2 to form four shorter helices from Mdvfmkglskakegvvaaaektkeg, vvhgvatvaektkeqvtnv and avaqktve. The residues in the C-terminal region don't show any intermolecular hydrogen bonds between the protein monomer Figure 3C. In the protein dimer, a slight unfolding near the residues EAP allowed the orientation of helices 1 and 2 towards each other forming the circular fold Figure 3D. Truncation of the $\mathrm{C}$-terminal region decreases the affinity with $\mathrm{Na}^{+}$and $\mathrm{Cl}^{-}$ions in $\alpha$-synuclein monomer compared to dimer. The secondary structure, content shows a higher percentage of unfolding in the protein monomer with $66.4 \%$ compared to dimmer with $51.4 \%$. Out of $10 \mathrm{Na}^{+}$, only 2 ions show interaction with the $\mathrm{C}$-terminal region of the protein. ${ }^{33-40}$ The higher number of sodium ions interacting with the negatively charged residues in the $\mathrm{N}$-terminal region unfolds helix-2 into three shorter helices from hgva, eqvt and gavvtgvtavaqktve Figure 3E. In the case of the protein dimer, the ionic interactions cause structural changes of one of the monomers by unfolding helix -1 and helix -2 into 
seven smaller helical fragments from fmkglskakegv, ktkqgvaea, egvv, tvaek, qvtnvggavvtg, vaqk and agsiaa. The Second Monomer Unfolds into Five shorter helices from vfmkglskakegvvaaaektkqgvaeaagk and kegv, atvae, gav and tavaqktvegagsiaaa. This unfolding allowed helix -1 of the two monomers to approach very closely to the $\mathrm{C}$ terminal region of the protein Figure 3F. These results show that $\mathrm{NaCl}$ exerts greater influence on the unfolding of helix -2 than helix -1 in both the monomer and dimer of $\alpha$-synuclein.

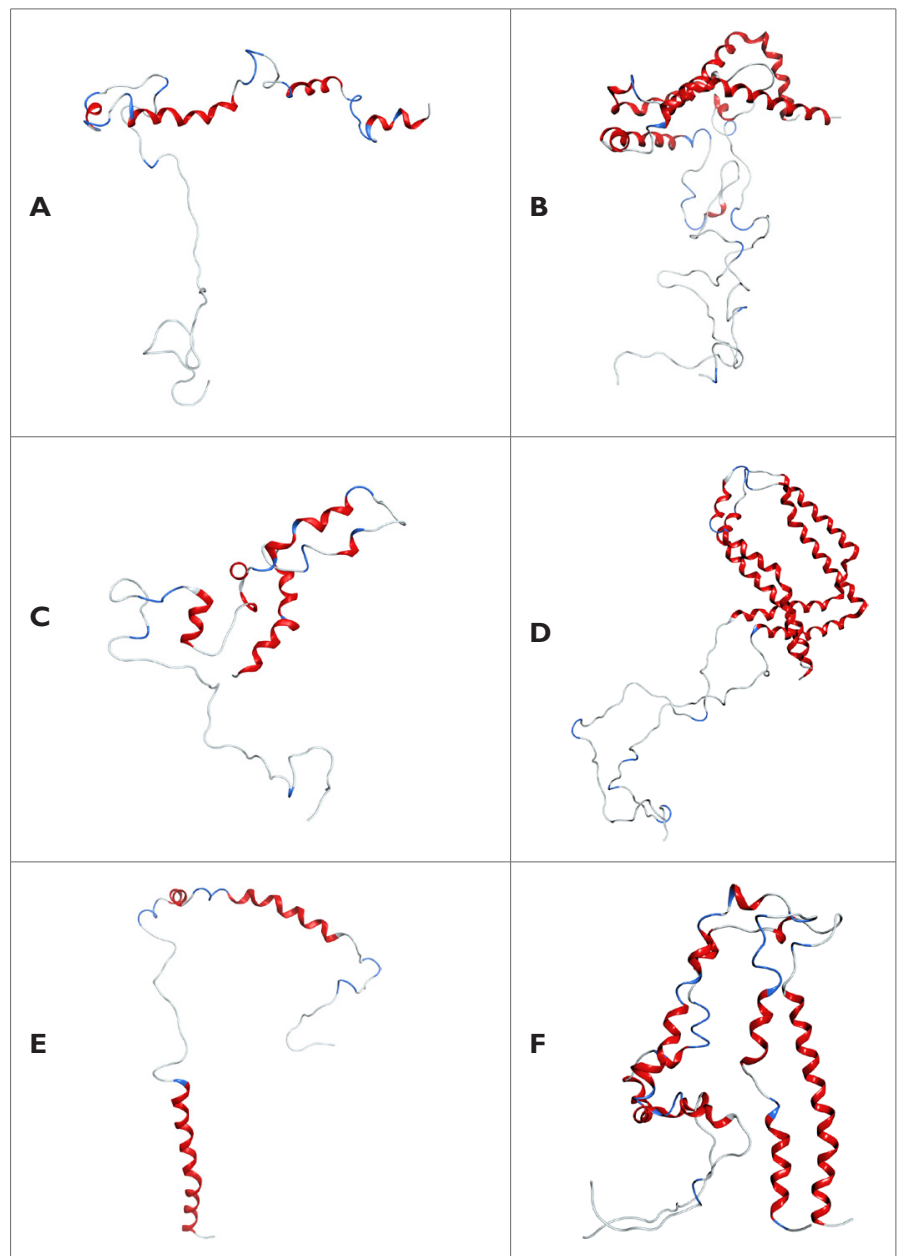

Figure 3 Conformations of $\alpha$-synuclein wild type (Figure \& B), mutant (Figure $C \& D$ ) and truncated forms (Figure E \& F) of both the monomer and dimer in the presence of $\mathrm{NaCl}$, generated at $30 \mathrm{~ns}$ of simulated trajectory

\section{MD simulations in the presence of $\mathrm{KCl}$}

Replacing $\mathrm{NaCl}$ with $\mathrm{KCl}$ allows the wild type monomer to show higher unfolded state with $78.6 \%$ compared to the dimer with $66.4 \%$ due larger size of the potassium ion compared to sodium. In total, $15 \mathrm{~K}^{+}$ binds to a protein monomer showing hydrogen bond interactions with glutamic and aspartic residues, respectively. The chloride ion doesn't show any hydrogen bonding interactions with the protein monomer. These ion-protein interactions neutralize the negative charge of the protein by the larger potassium ions while the positively-charged residues move freely in solution. The unfolding of the protein near the residues vvaa allowed helix -1 to unfold into two smaller helical fragments of mdvfmkglskakeg and aaektq. Much of the helix-2 is unfolded except in the regions tkeqv and avaqktve Figure 4A. In the case of the protein dimer $31 \mathrm{~K}^{+}$and $22 \mathrm{Cl}^{-}$ions bind to protein surface neutralizing both the negative and positive charge of the protein causing structural changes at the end of helix -1 by extending the loop between helix -1 and helix -2 . The helix -2 is unfolded into two shorter helices from kegvvhgvatvaektkeqvtn and avaqktve of monomer-1 and from vvhgvatvaektkeq tgvtavaqk of the monomer-2 Figure 4B. This showed that a higher percentage of unfolding is seen in the NAC region (61-95) in both the monomer and dimer in the presence of $\mathrm{KCl}$ than in $\mathrm{NaCl}$ salt solution. The helical content of the mutant Ala30Pro decreases to $25.7 \%$ with $74.3 \%$ of unfolded protein compared to $\mathrm{NaCl}$ salt solution. The ionic interactions of protein monomer cause breaks in the helices -1 and 2 to form smaller fragments of mkglskakegvvaaaekeapg, egvvhgvatvae and vaqk Figure 4C. In the protein dimer, both these helices do not undergo pronounced structural changes except at VV of one of the monomers, unfolding helix-2 into two smaller fragments. This unfolding causes the orientation of helix -2 very close to helix -1 with a tight network of interactions creating the helical formation of the $\mathrm{C}$-terminal regions with the residues Dqlg and Pdne Figure 4D. This showed that $\mathrm{KCl}$ doesn't exert great influence on the misfolding of the $\alpha$-synuclein dimer compared to the monomer in the $\mathrm{N}$-terminal helices. Truncated protein shows no affinity with $\mathrm{K}^{+}$for the protein monomer but shows less affinity for the protein dimer with $10 \mathrm{~K}^{+}$ions bound to it. Both these forms of the protein showed affinity with chloride ions with 8 and $15 \mathrm{Cl}^{-}$ions, respectively. The secondary structure content showed higher percentage of unfolded regions in the monomer than dimer with $66.4 \%$ and $44.1 \%$ respectively. The protein monomer also showed $3.6 \%$ more of the beta sheet contents than dimer. Due to a higher number of chloride ions, the negative charge of the protein is mostly neutralized in both the forms of the protein. The positively-charged residues are partially neutralised in the dimer while the residues move freely in the protein monomer. This causes the protein monomer to show a more visibly unfolded structure compared to the dimer. This unfolding of the protein monomer allowed helix-1 to unfold into two smaller fragments of the residues from kglskakeg and ektk, eaagvvhgvatvaekte and avvt. This form of unfolding rearranges the $\mathrm{C}$-terminal region of the protein Ala and the to form an antiparallel beta sheet with Val and Lys Figure 4E. In the protein dimer, the helix -1 of monomer-1 does not unfold while it shows unfolding near the imperfect repeat egv of monomer-2 into two shorter helices from vfmkglskak and vaaaektkqgvaeaagktk. The helix-2 of both the monomers is broken down to three and two shorter helices from egvvhgvat, tkeq of monomer-1 and from avvtgvtavaqktvegagsiaaa, kegvvhgvatvaektkeq and vtavaqktvegagsiaaa of monomer-2. This form of folding creates a circular fold for the protein dimer Figure $4 \mathrm{~F}$. This showed that the truncation of the protein allowed helix -1 to approach close to the $\mathrm{C}$-terminal region to form a tight network of interactions in both the forms of the protein.

\section{MD simulations in the presence of $\mathrm{CaCl}_{2}$}

In the presence of $\mathrm{CaCl}_{2}$, the content of secondary structure is higher by $66.4 \%$ in the protein monomer compared to the dimer with $44.3 \%$. Out of the $27 \mathrm{Ca}^{2+}$ that binds to the protein monomer, only $5 \mathrm{Ca}^{2+}$ ions bind to the $\mathrm{N}$-terminal region of the protein while the rest of the $\mathrm{Ca}^{2+}$ ions show interactions with the $\mathrm{C}$-terminal region of the protein. Because of the influence of a large number of $\mathrm{Ca}^{2+}$ ions near the $\mathrm{C}$-terminal region of the protein, the residues Profaned Ser 
forms an anti-parallel beta sheets with Tyr and Glen. The unfolding of the protein near the residues allowed helix -1 to unfold into two helical fragments of mdvfmkglskake and aaektkqgv. Much of the helix -2 is unfolded except in the regions Figure 5A. In the case of the dimer, the ionic interaction doesn't show much influence on the protein unfolding, except the helix 2 of one of the monomer is unfolded at the region Figure 5B. This show that $\mathrm{Ca}^{2+}$ has a much greater influence of the $\mathrm{C}$-terminal region compared to the rest of the protein in both the monomer and dimer of $\alpha$-synuclein. In the mutant Ala30Pro, the percentage of unfolding is shown with $27.9 \%$ of helix and $72.1 \%$ of loop content. In total, $21 \mathrm{Ca}^{2+}$ and $12 \mathrm{Cl}^{-}$ions bind to the surface of the protein showing ionic interactions with 16 glutamic and 5 aspartic acid residues. Out of the $21 \mathrm{Ca}^{2+}$ ions that bind to the protein monomer, six $\mathrm{Ca}^{2+}$ ions bind to the $\mathrm{N}$-terminal helix-1 of the protein and three $\mathrm{Ca}^{2+}$ ions show interactions with the helix -2 region of the protein. Most of the chloride ions interact with lysine residues in both the $\mathrm{N}$ - and $\mathrm{C}$-terminal regions of the protein neutralizing the positive charge of the protein. This ionic interaction of chloride ions influences the $\mathrm{N}$-terminal region of the helix -1 to completely unfold into two shorter helices with the residues from aaektkqgvaeapgktk,

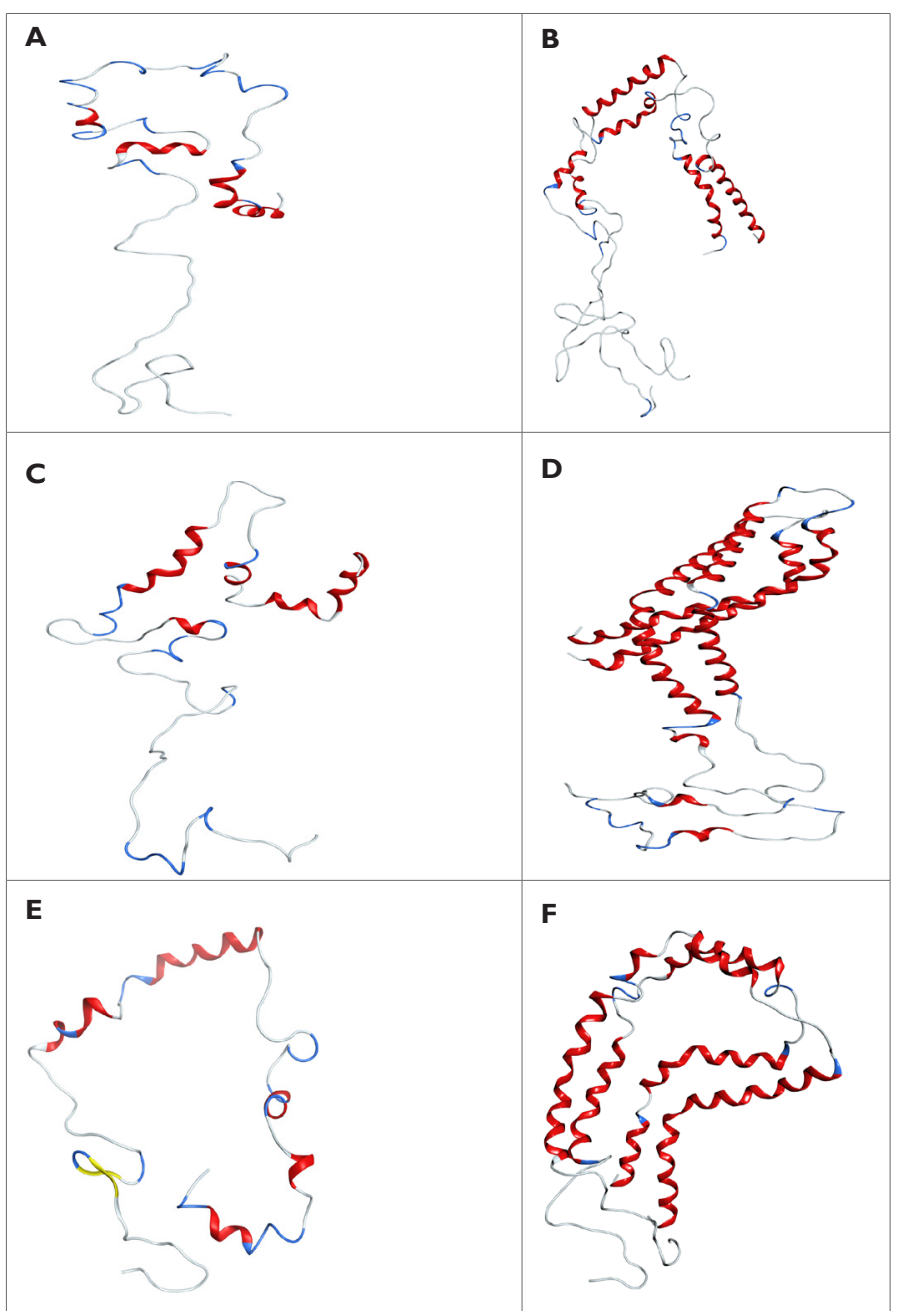

Figure 4 Conformations of $\alpha$-synuclein wild type (Figure A \& B), mutant (Figure C \& D) and truncated forms (Figure E \& F) of both the monomer and dimer in the presence of $\mathrm{KCl}$, generated at 30 ns of simulated trajectory hgvatvaektkeqvtnvggavvtg and ktvegagsiaaa. This unfolding allows an $\mathrm{N}$-terminal region of the helix-1 to rearrange very close to the C-terminal in a triangular form Figure 5C. In the protein dimer, the helix-2 unfolds into two shorter helices with the residues from of monomer-2. The residues in the $\mathrm{C}$-terminal region of the protein Glu and Glu form anti-parallel beta sheets with Asp and Tyr Figure 5D. These results show that calcium ions exert much influence on the $\mathrm{C}$ terminal region of the protein in the formation of beta sheets. Truncated protein shows a decrease in the percentage of unfolding with $42.7 \%$ in the protein dimer compared to monomer with $44.5 \%$. In total, $9 \mathrm{Ca}^{2+}$ and $16 \mathrm{Cl}^{-}$ions bind to the protein monomer while $24 \mathrm{Ca}^{2+}$ and $13 \mathrm{Cl}^{-}$ ions bind to the protein dimer. The ionic interactions of $\mathrm{Ca}^{2+}$ do not show much influence on helix-1 but influence helix -2 to unfold into shorter helices from Vatvaektequt and avvtgvtavaqktvegag Figure 5E. In the protein dimer, the helices show unfolding near the residues in helix -2 of one monomer -1 and ggavvtgv of the other monomer -2 . This unfolding of helix -2 into two helices from of the monomer-2 Figure 5F. These results show that truncation of the protein exerts less influence on helix -1 in protein unfolding in both the forms.

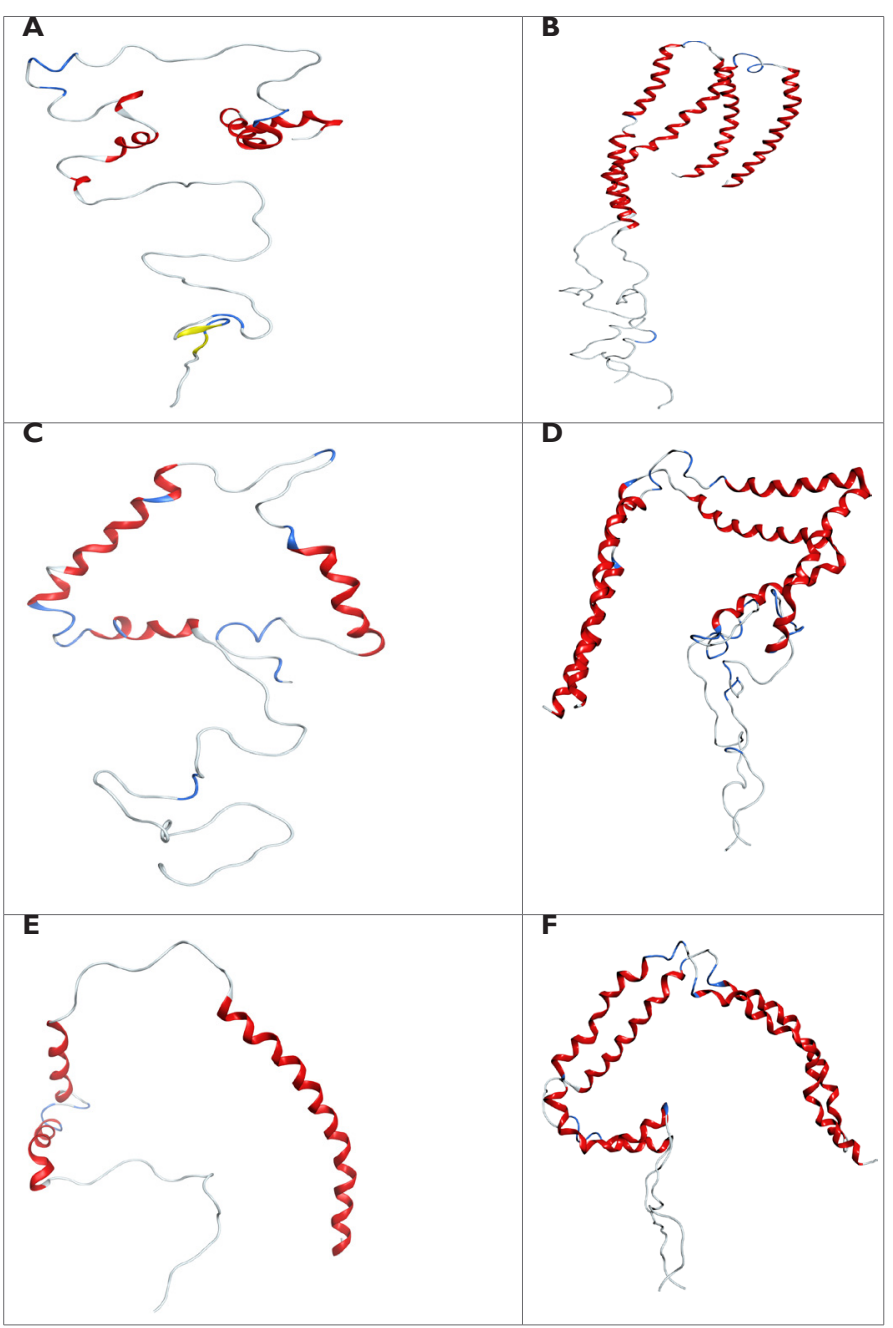

Figure 5 Conformations of $\alpha$-synuclein wild type (Figure $\mathrm{A} \& \mathrm{~B}$ ), mutant (Figure $C \& D$ ) and truncated forms (Figure E \& F) of both the monomer and dimer in the presence of $\mathrm{CaCl}_{2}$, generated at $30 \mathrm{~ns}$ of simulated trajectory 


\section{MD simulations in the presence of $\mathrm{MgCl}_{2}$}

Replacing $\mathrm{CaCl}_{2}$ with $\mathrm{MgCl}_{2}$ shows fewer Minds to the protein monomer and a greater number of Minds to the protein dimer in comparison to $\mathrm{Ca}^{2+}$ ions. The overall secondary structure content shows a higher percentage of unfolding for the protein monomer with $72.1 \%$ compared to the dimer. The helix -1 of the protein monomer resists unfolding while helix -2 unfolds into two shorter helices from Figure $6 \mathrm{~A}$. In the protein dimer, one of the monomers is highly unfolded into shorter fragments of and at the same time, the other monomer unfolds into four shorter helices with the residues from the residues in the $\mathrm{C}$-terminal region form anti-parallel beta sheets with Figure $6 \mathrm{~B}$. These results suggest that $\mathrm{CaCl}_{2}$ and $\mathrm{MgCl}_{2}$ induce two opposing effects of compaction and unfolding on $\alpha-$-synuclein depending on the divalent cation concentration. Thus, $\mathrm{Ca}^{2+}$ is more preferred to bind to an irregularly shaped $\mathrm{C}$-terminal over $\mathrm{Mg}^{2+}$. Interaction of metal ions with the protein also shows that these two ions, Mand $\mathrm{Ca}^{2+}$, exhibit negligible interactions with amino groups. That is, the determined stability constants of these metal ions with Asp only relate to interactions between metal ions and carboxyl groups. In the protein mutant, Ala30 Pro, the secondary structure content shows $25 \%$ of helix and $2.9 \%$ of the beta sheet. Out of $19 \mathrm{Mg}^{2+}, 16 \mathrm{Mions}$ bind to the C-terminal, 2 Miens bind to helix-1 and one Mind to the carboxylate side chains of Glue and Asp. Fewer Miens binding to the $\mathrm{N}$-terminal allow helix -1 and helix-2 to unfold into two shorter helices from Figure $6 \mathrm{C}$. In the protein dimer, the helix -1 of monomer- 1 does not unfold while it shows unfolding near the residues in helix-1 of monomer-2. The helix -2 of both the monomers bends to a $\mathrm{V}$ shape without unfolding and create inter molecular interactions in the $\mathrm{C}-$ terminal region of the protein Figure 6D. Truncated protein shows $46.4 \%$ of helix and $53.6 \%$ of unfolded protein with $0 \%$ of the beta sheet. Out of $19 \mathrm{Mg}^{2+}, 4$ ions bind to the $\mathrm{N}$-terminal while the rest bind to the carboxylate side chains of Glutamic acid. Fewer Miens binding to the $\mathrm{N}$-terminal do not influence much the conformational changes of helix-1 while they unfold helix-2 into two shorter helices from Figure $6 \mathrm{E}$. In the protein dimer, the helix -1 of one of the monomers does not unfold while it shows unfolding near the residues of the other monomer unfolding helix -1 into three helices from. The helix -2 of both the monomers is unfolded to four and two helices from Figure

\section{MD simulations in the presence of $\mathrm{ZnCl}_{2}$}

In the presence of $\mathrm{ZnCl}_{2}$, the secondary structure content of monomer shows a higher percentage of unfolding with $65.7 \%$ compared to the dimer with $61.4 \%$. In total, $14 \mathrm{Zn}^{2+}$ and $25 \mathrm{Zn}^{2+}$ ions bind to the protein monomer and dimer, respectively. The interactions of chloride ions with the positively-charged amino acids influence helix -1 of the protein monomer to unfold into two shorter helices from Figure 7A. In the case of the protein dimer, monomer-1 undergoes structural changes in the $\mathrm{N}$-terminal helix-1 by breaking the helix into two shorter helices from. The helix-2 becomes unfolded, giving rise to three shorter helices from. The $\mathrm{N}$-terminal helix of the monomer-2 doesn't undergo pronounced structural changes while the helix-2 unfolds to form three shorter helices from Figure 7B. The mutant $\alpha$-synuclein shows $37.1 \%$ of helix and $62.9 \%$ of unfolded regions with $0 \%$ of the beta sheet. Out of six $\mathrm{Zn}^{2+}$, four $\mathrm{Zn}^{2+}$ binds to the $\mathrm{C}$-terminal and the two ions bind to the $\mathrm{N}$-terminal. These ionic interactions of chloride ions with the positively-charged amino acids
$6 \mathrm{~F}$. These results show that helix -1 shows a different behavior in these two forms of the protein.

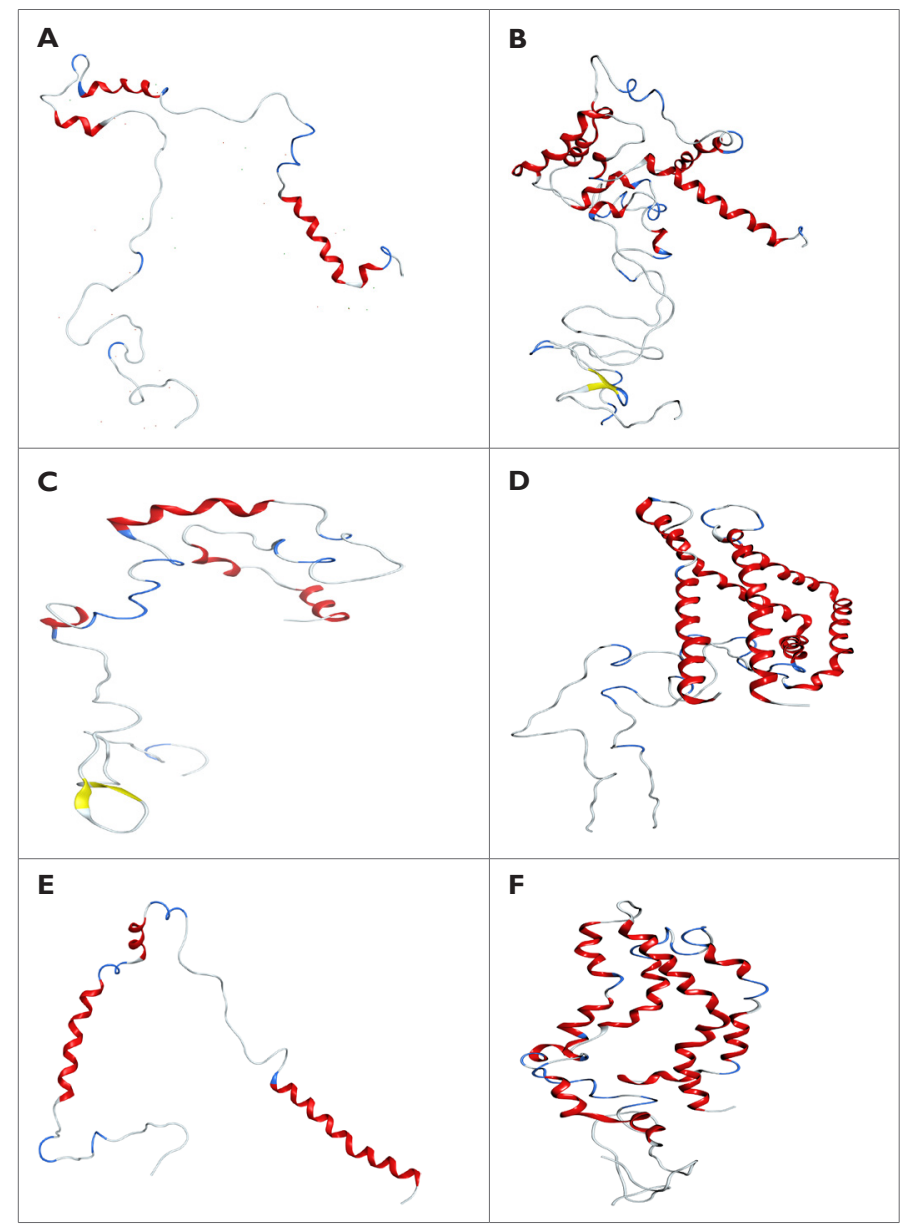

Figure 6 Conformations of $\alpha$-synuclein wild type (Figure A \& B), mutant (Figure $C \& D$ ) and truncated forms (Figure E \& F) of both the monomer and dimer in the presence of $\mathrm{MgCl}_{2}$, generated at $30 \mathrm{~ns}$ of simulated trajectory

influence helix-1 to break into three shorter helices from. Moreover, helix -2 is unfolded into three smaller helices from Figure 7C. In the protein dimer, the helix -1 of both monomers does not unfold while it shows unfolding near the residues in helix -2 of the both the monomers. This folding bends helix -2 to a $\mathrm{V}$ shape, arranging both the helices very close to each other Figure 7D. Finally, the truncated protein decreases the affinity with $\mathrm{Zn}^{2+}$ and $\mathrm{Cl}^{-}$with $7 \mathrm{Zn}^{2+}$ and $5 \mathrm{Cl}^{-}$ ions. These ionic interactions of $\mathrm{Zn}^{2+}$ with the negatively-charged amino acids influence helix-1 to unfold into two shorter helices from. Moreover, helix-2 is broken down into two smaller helices from Figure 7E. In the protein dimer, the helix-1 of one of the monomers does not unfold while it shows unfolding near the imperfect repeats of the other monomer unfolding the helix -1 into three shorter helices from. The helix-2 of both the monomers is unfolded to two and three helices from of one monomer of the other monomer. This form of folding creates a triangular fold for the protein dimer Figure 7F. 


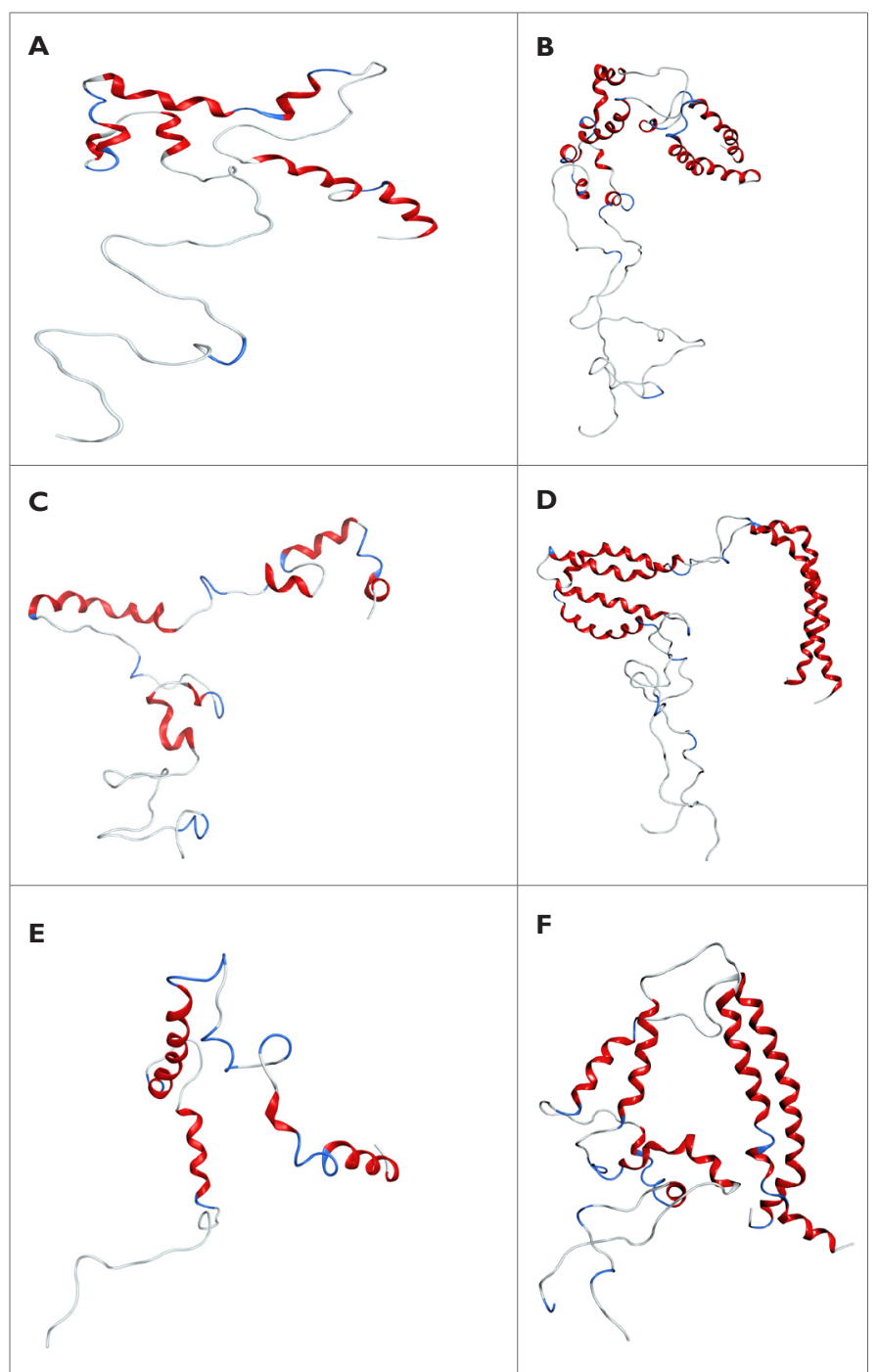

Figure 7 Conformations of $\alpha$-synuclein wild type (Figure A \& B), mutant (Figure $C \& D$ ) and truncated forms (Figure E \& F) of both the monomer and dimer in the presence of $\mathrm{ZnCl}_{2}$, generated at 30ns of simulated trajectory

\section{Discussion}

Overall, there are slightly strong affinities with $\mathrm{Na}^{+}$and $\mathrm{K}^{+}$ions with negatively-charged residues of $\alpha$-synuclein compared to $\mathrm{Ca}^{2+}$, Mand $\mathrm{Zn}^{2+}$ based on the number of captions interacting with $\alpha-$ synuclein dimer, mutant monomer and mutant dimer Table 1. Since, $\mathrm{Ca}^{2+}$, Mand $\mathrm{Zn}^{2+}$ possesses different radii with similarity in charges, their affinity and coordination number between them and $\alpha$-synuclein appears to be different. $\mathrm{Ca}^{2+}$ ions bind mainly to the oxygen of carbonyl groups of residues in proteins. The binding sites for these metal ions are situated in the region of the oxygen atoms of Asp and Glue residues mainly through a $\mathrm{C}=\mathrm{O}$ group in a protein, which can result in the conformational transition from a helix to a sheet or turn species. This conformational stability of $\alpha$-synuclein varies with different metal ions based on their characteristic features. From Table 2 it is clear that $\mathrm{Zn}^{2+}$ shows higher stability in both wild and mutant forms of the protein, while $\mathrm{Ca}^{2}+$ increased the stability of a truncated form of the monomer. The other metal ion, Shows high influence in enhancing the stability of truncated form but destabilizes the mutant form compared to wild type with $2.9 \%$ of the $\beta$-sheet. In comparison to $\mathrm{NaCl}, \mathrm{KCl}$ decreases the stability of all the three forms of the protein showing much influence on protein aggregation in the truncated form with $3.6 \%$ of the $\beta$-sheet compared to mutant with $2.9 \%$. These results show that effect of $\alpha$-synuclein aggregation is seen high in the truncated form compared to other forms of the protein. Previous data on experimental studies of human $\alpha$-synuclein truncation from 1-87,1-102,1-110,1-119 and 1-120 showed a faster rate of aggregation compared to full length and mutant protein. Moreover, partially truncated $\alpha$-synuclein has been detected in dementia patients with Lewy body (DLBs) brains, glial cytoplasmic inclusions (GCIs) of multiple system atrophy (MSA) and abnormal neurites of Alzheimer's disease without $\mathrm{LBs}^{38}$, suggesting that $\mathrm{C}$ terminal truncations may play a role in the aggregation of $\alpha$-synuclein. These results also show that, the unfolding of the protein monomer is reduced in the presence of $\mathrm{MgCl}_{2}$ by $27.9 \%$, and $25 \%$ of the wild and mutant forms, respectively. However, decreased unfolding was seen in the presence of $\mathrm{KCl}$ with truncated form of protein monomer. In the dimeric form, the unfolding is less pronounced in the presence of $\mathrm{CaCl}_{2}$ by $55.5 \%, 57.5 \%$ and $57.3 \%$, respectively, in all the three forms of the protein Table 3. Interestingly, the unfolding of $\alpha$-synuclein monomer in the presence of $\mathrm{K}^{+}$ions increases substantially, compared to other metal ions presumably due to the loss of the coordination bonds. This loss of hydrophobic and hydrogen-bond interactions rearranges the $\alpha$-synuclein to more compact conformations with favorable long-range electrostatic interactions. Based on the change in the secondary structure content of $\alpha$-synuclein monomer, $\mathrm{Na}^{+}$, and $\mathrm{K}^{+}$ions decrease the stability of the helix in the unfolding process of wild and truncated forms. In comparison, only $\mathrm{K}^{+}$ions decrease the percentage of helical content of Ala30Pro mutant equally to $\mathrm{Mg}^{2+}$. This is due to the presence of $\mathrm{Na}^{+}$, and $\mathrm{K}^{+}$ions between the helices at the loops destabilize the helix structure while the ionic interactions of $\mathrm{Ca}^{2+}$, Mand $\mathrm{Zn}^{2+}$ ions increase the helix structure by stabilizing the hydrogen bonds. Overall, the results also show that binding of $\mathrm{Ca}^{2+}$, Mand $\mathrm{K}^{+}$ions with $\alpha$-synuclein wild, mutant and truncated forms of the monomer will influence the aggregation rate of $\alpha$-synuclein with $2.9 \%$ of the beta sheet in $\mathrm{CaCl}_{2}, \mathrm{Mg} \mathrm{Cl}_{2}$ and $3.6 \%$ in $\mathrm{KCl}$ Table 2. It has been proposed that the aggregation of $\alpha$-synuclein inside the neurons can be influenced by the increased intra-cytoplasmic $\mathrm{Ca}^{2+}$ concentration. ${ }^{41,42}$ In addition, the interaction of $\alpha$-synuclein with the cell membranes was modulated by $\mathrm{Ca}^{2+}$. The absence of $\mathrm{Ca}^{2+}$ allows $\alpha$-synuclein to interact with lipid membranes via the $\mathrm{N}$-terminal domain. The additional interaction between the membrane and the $\mathrm{C}-$ terminal domain can be enhanced by the addition of $\mathrm{Ca}^{2+}$, which may lead to aggregation of this protein. For $\mathrm{Ca}^{2+}$ ions, there are many strong-binding sites in the surface residues (Asp or Glue) of $\alpha-$ synuclein, which influences the stability of the tertiary structure. In addition, the results obtained for the wild type dimer reveals that $\mathrm{KCl}$ shows a significant effect in unfolding, while $\mathrm{ZnCl}_{2}$ and $\mathrm{NaCl}$ shows almost equal effect on the protein dimer stability in all the three forms Table 3. However, $\mathrm{CaCl}_{2}$ showed much influence on protein aggregation in mutant (A30P) dimer. Recent evidences also show that the toxicity of the oligomerized $\alpha$-synuclein can be abolished by preventing the $\mathrm{Ca}^{2+}$ influx through removal of extracellular $\mathrm{Ca}^{2+}$. The finding also supports the fact that $\beta$ sheet-rich oligomerized species are the most toxic species in cells, and that this toxicity is crucially dependent on $\mathrm{Ca}^{2+}$ dysregulation. ${ }^{43}$ Furthermore, $\mathrm{MgCl}_{2}$ decreases the stability of wild type and truncated forms of the dimer, while it shows 
equal effect along with $\mathrm{NaCl}$ in the mutant form of the protein. Mutation of Ala30pro clearly shows that both the monovalent and divalent cations decrease the stability of $\alpha$-synuclein in both the forms of the protein. These results show that binding of these metal ions with positively- and negatively-charged residues disturbs the secondary structure content of the protein by breaking the helices 1 and 2 into smaller helices. This breakage of alpha helices differs with different salt concentrations in all the three types of the protein in both the monomer and dimer. In all these salts except $\mathrm{MgCl}_{2}$, the residues in the $\mathrm{N}$-terminal helix-1 from are highly stable without undergoing any structural changes in the rest of the wild type monomer. But in the case of the mutant protein, the N-terminal helix-1 is highly disturbed undergoing a structural helix-to-flexible loop transition. When the residues from 110-140 regions are truncated, the residues in the $\mathrm{N}$ terminal helix -1 are highly disturbed undergoing a structural transition from helix -1 to flexible loops in the presence of $\mathrm{NaCl}, \mathrm{MgCl}_{2}$ and $\mathrm{ZnCl}_{2}$ with the exception of $\mathrm{CaCl}_{2}$ enhancing the stability of helix-1. However, with $\mathrm{KCl}$, the $\mathrm{N}$-terminal helix-1 forms antiparallel beta sheet as shown in Figure 4E. These results predict that in both the mutant and truncated forms, the $\mathrm{N}$-terminal helix -1 undergoes a less pronounced structural transition compared to the wild type. The orientation of the affected residues in the $\mathrm{N}$-terminal helix-1 differs with different salts. In $\mathrm{MgCl}_{2}$ and $\mathrm{ZnCl}_{2}$, the helix-1 is oriented away from the rest of the protein without showing any contacts with the protein while the orientation is very close to other helices in the presence of other salts showing very strong intra-molecular hydrogen bonds. This orientation of helix-1 reveals that aggregation of $\alpha$ synuclein in the presence of $\mathrm{MgCl}_{2}$ and $\mathrm{ZnCl}_{2}$ is less pronounced compared to $\mathrm{NaCl}, \mathrm{KCl}$ and $\mathrm{CaCl}_{2}$. AFM (Atomic Force Microscopy) images show that $\alpha$-synuclein fibrils prepared for lower concentrations of $\mathrm{NaCl}$ have a ribbon-like morphology, while those prepared in higher concentrations are twisted and rod-like. ${ }^{44}$ In the form of dimer, $\mathrm{MgCl}_{2}$ showed a high effect of unfolding of alpha helices in both wild and truncated forms, while $\mathrm{ZnCl}_{2}$ showed effects on Ala30Pro mutant Table 3. Thus, it can be stated that $\mathrm{Na}^{+}$, and $\mathrm{K}^{+}$ions weaken the conformational stability of $\alpha$-synuclein wild type and truncated forms of the monomer, while $\mathrm{Ca}^{2+}$ and $\mathrm{Zn}^{2+}$ ions enhance the conformational stability in all the three forms Table 1. However, shows different effect on different forms of the protein. These ions show the opposite effect in the form of protein dimer indicating that the loss of solventexposed surface of the $\alpha$-synuclein is greater in the unfolding process than that about $\alpha$-synuclein without metal ions Table 2. Studies also show that the propensity for the Leu-substituted $\alpha$-synuclein to oligomerized is decreased in the presence of $\mathrm{ZnCl}_{2}$, indicating the influence of $\mathrm{Zn}^{2+}$ on the fibrillation pathway to $\alpha$-synuclein. ${ }^{45} \mathrm{~A}$ recent study made a compelling argument with the involvement of zinc dyshomeostasis as a trigger for Alzheimer disease which is involved in both beta amyloid aggregation and taupathy ${ }^{46} \mathrm{It}$ is entirely plausible that zinc and other metal ions play a substantial role in other neurodegenerative diseases such as Parkinson's. ${ }^{47}$ Thus, these results suggest that unfolding of $\alpha$-synuclein differs in different salt concentrations due to the influence of different metal ions at the $\mathrm{C}$ terminal and $\mathrm{N}$-terminal residues predicting to be the two major binding sites of $\alpha$-synuclein. Previously, the results indicate that Participates in the coordination with $\mathrm{NH} 2$ while $\mathrm{Ca}^{2+}$ coordinates with $\mathrm{COO}^{-}$. Also, proton shift changes at $\mathrm{pH}$ above 8 upon coordination of Asp with Miss much greater in solutions with $\mathrm{Ca}^{2+}$. In addition, $\mathrm{Na}^{+}$is more strongly attracted to the protein surface than $\mathrm{K}^{+}$. This is primarily due to interactions with $\mathrm{COO}^{-}$side chain groups of Asp and Glu. ${ }^{48}$ Experimental studies reveal that the binding site -1 of $\alpha$-synuclein is driven by the electrostatic interactions of the negatively-charged side chains with metal ions and is mostly directed towards the C-terminal domain of the protein. The metal-binding site- 2 has been assigned to several N-terminal residues and to the imidazole ring of the sole histamine residue. ${ }^{49}$ Experimental studies support this statement by demonstrating that the $\mathrm{C}$-terminus of $\alpha$-synuclein also contain a specific, albeit low-affinity, metal binding site. The binding of the metal ion at this sequence is not only influenced by electrostatic interactions, but also by the residues of the $\mathrm{C}$-terminal portion of the $\alpha$-synuclein. These propensities for the metal ion induce partial folding of the non-oxidized $\alpha$-synuclein and promote the formation of fibrillation. ${ }^{50,51}$ Among the most effective stimulators $\mathrm{Cu}^{2+}$ and $\mathrm{Fe}^{2+}$ ions interact specially with $\alpha$-synuclein while $\mathrm{Al}^{3+}, \mathrm{Co}^{3+}$, and $\mathrm{Mn}^{2+}$ interact non-specifically and influence partial folding of the protein and subsequent fibrillation. ${ }^{51}$ The interaction of these metal ions in different ways of $\alpha$-synuclein induces a wide range of structural changes in the native conformation of $\alpha$-synuclein. These structural changes vary from an ordered structure of residues to a globule-like conformation in the presence of some monovalent metals and later promoted by interaction with polyvalent ions. These structural and morphological changes of partially folded monomeric and dimeric forms can assemble into different oligomers and fibrils.

Table I $\alpha$-synuclein and salts simulation data

\begin{tabular}{|c|c|c|c|c|c|c|}
\hline & Monomer WT & $\begin{array}{l}\text { Monomer } \\
\text { Mutant }\end{array}$ & $\begin{array}{l}\text { Monomer } \\
\text { Truncated }\end{array}$ & Dimer WT & $\begin{array}{l}\text { Dimer } \\
\text { Mutant }\end{array}$ & $\begin{array}{l}\text { Dimer } \\
\text { Truncated }\end{array}$ \\
\hline Size of box, $\mathrm{X}, \mathrm{Y}, \mathrm{Z}$ dimensions & $10 \times 20$ & $10 \times 20$ & $10 \times 20$ & $10 \times 20$ & $10 \times 20$ & $10 \times 20$ \\
\hline \multirow{3}{*}{$\begin{array}{l}\text { Number of water molecules in } \\
\text { box Water/Metal ratio }\end{array}$} & 9238 & 9244 & 8270 & 9216 & 9217 & 9068 \\
\hline & 17.7 & \multirow{2}{*}{14.4} & \multirow{2}{*}{23.7} & 16.3 & 12.3 & \multirow{2}{*}{18.8} \\
\hline & 14.4 & & & 16.6 & 12.5 & \\
\hline $\mathrm{NaCl}$ & 521 & 644 & 348 & 564 & 748 & 482 \\
\hline Number of $\mathrm{Na}$ ions & 512 & 635 & 350 & 546 & 730 & 487 \\
\hline Number of $\mathrm{Cl}$ ions & 9 & 9 & -2 & 18 & 18 & -5 \\
\hline $\mathrm{KCl}$, & 521 & 644 & 348 & 564 & 748 & 482 \\
\hline
\end{tabular}




\begin{tabular}{|c|c|c|c|c|c|c|}
\hline & Monomer WT & $\begin{array}{l}\text { Monomer } \\
\text { Mutant }\end{array}$ & $\begin{array}{l}\text { Monomer } \\
\text { Truncated }\end{array}$ & Dimer WT & $\begin{array}{l}\text { Dimer } \\
\text { Mutant }\end{array}$ & $\begin{array}{l}\text { Dimer } \\
\text { Truncated }\end{array}$ \\
\hline Number of $\mathrm{K}$ ions & 512 & 635 & 350 & 546 & 590 & 487 \\
\hline Number of $\mathrm{Cl}$ ions & 9 & 9 & -2 & 18 & 18 & -5 \\
\hline $\mathrm{CaCl}_{2}$ & 642 & 640 & 348 & 555 & 739 & 483 \\
\hline Number of $\mathrm{Ca}$ ions & 1275 & $127 \mid$ & 698 & 1092 & 1460 & 970 \\
\hline Number of $\mathrm{Cl}$ ions & 9 & 9 & -2 & 18 & 18 & -4 \\
\hline $\mathrm{MgCl}_{2}$ & 642 & 640 & 348 & 555 & 739 & 483 \\
\hline Number of $\mathrm{Mg}$ ions & 1275 & |27| & 698 & 1092 & 1460 & 970 \\
\hline Number of $\mathrm{Cl}$ ions & 9 & 9 & -2 & 18 & 18 & -4 \\
\hline $\mathrm{ZnCl}_{2}$ & 642 & 640 & 348 & 555 & 739 & 483 \\
\hline Number of $\mathrm{Zn}$ ions & 1275 & |27| & 698 & 1092 & 1460 & 970 \\
\hline Number of $\mathrm{Cl}$ ions & 9 & 9 & -2 & 18 & 18 & -4 \\
\hline
\end{tabular}

Table 2 Secondary structure content for the 30 ns simulated structure of $\alpha$-synuclein monomer predicted using 2 struc server

\begin{tabular}{|c|c|c|c|c|}
\hline Salt & \%Helix & \%Sheet & \%Loop & Number of lons \\
\hline $\mathrm{NaCl}$ & 27.1 & 0 & 72.9 & $29 \mathrm{Na}^{+}, 5 \mathrm{Cl}^{-}$ \\
\hline $\mathrm{KCl}$ & 21.4 & 0 & 78.6 & $15 \mathrm{~K}^{+}, \mathrm{IICl}$ \\
\hline $\mathrm{CaCl}_{2}$ & 30.7 & 2.9 & 66.4 & $27 \mathrm{Ca}^{2+}, \mathrm{IICl}^{-}$ \\
\hline $\mathrm{MgCl}_{2}$ & 27.9 & 0 & 72.1 & $23 \mathrm{Mg}^{2+}, 12 \mathrm{Cl}^{-}$ \\
\hline $\mathrm{ZnCl}_{2}$ & 34.3 & 0 & 65.7 & $14 \mathrm{Zn}^{2+}, 13 \mathrm{Cl}^{-}$ \\
\hline \multicolumn{5}{|c|}{ Ala30Pro } \\
\hline $\mathrm{NaCl}$ & 32.9 & 0 & 67.1 & $22 \mathrm{Na}^{+}, \mathrm{ICl}^{-}$ \\
\hline $\mathrm{KCl}$ & 25.7 & 0 & 74.3 & $\mathrm{IIK}^{+}, 5 \mathrm{Cl}^{-}$ \\
\hline $\mathrm{CaCl}_{2}$ & 31.4 & 0 & 68.6 & $2 \mathrm{ICa}^{2+}, 12 \mathrm{Cl}^{-}$ \\
\hline $\mathrm{MgCl}_{2}$ & 25 & 2.9 & 72.1 & $19 \mathrm{Mg}^{2+}, 14 \mathrm{Cl}^{-}$ \\
\hline $\mathrm{ZnCl}_{2}$ & 37.1 & 0 & 62.9 & $6 \mathrm{Zn}^{2+}, 11 \mathrm{Cl}^{-}$ \\
\hline \multicolumn{5}{|c|}{ Truncation } \\
\hline $\mathrm{NaCl}$ & 33.6 & 0 & 66.4 & $10 \mathrm{Na}^{+}, 8 \mathrm{Cl}^{-}$ \\
\hline $\mathrm{KCl}$ & 30 & 3.6 & 66.4 & $0 \mathrm{~K}^{+}, 8 \mathrm{Cl}^{-}$ \\
\hline $\mathrm{CaCl}_{2}$ & 55.5 & 0 & 44.5 & $9 \mathrm{Ca}^{2+}, 16 \mathrm{Cl}^{-}$ \\
\hline $\mathrm{MgCl}_{2}$ & 46.4 & 0 & 53.6 & $10 \mathrm{Mg}^{2+}, 7 \mathrm{Cl}^{-}$ \\
\hline $\mathrm{ZnCl}_{2}$ & 39.1 & 0 & 60.9 & $7 \mathrm{Zn}^{2+}, 5 \mathrm{Cl}^{-}$ \\
\hline
\end{tabular}

Table 3 Secondary structure content for the 30 ns simulated structure of $\alpha$-synuclein dimer predicted using 2 struc server

\begin{tabular}{lllll}
\hline Salt & \%Helix & \%Sheet & \%Loop & Number of lons \\
\hline $\mathrm{NaCl}$ & 40.7 & 0 & 59.3 & $53 \mathrm{Na}^{+}, 7 \mathrm{Cl}$ \\
$\mathrm{KCl}$ & 33.6 & 0 & 66.4 & $3 \mathrm{~K}^{+}, 22 \mathrm{Cl}$ \\
$\mathrm{CaCl}_{2}$ & 55.7 & 0 & 44.3 & $35 \mathrm{Ca}^{2+}, 13 \mathrm{Cl}^{2-}$ \\
$\mathrm{MgCl}_{2}$ & 32.1 & 0 & 67.9 & $38 \mathrm{Mg}^{2+}, 17 \mathrm{Cl}^{2-}$ \\
$\mathrm{ZnCl}$ & 38.6 & 0 & 61.4 & $25 \mathrm{Zn}^{2+}, 20 \mathrm{Cl}^{-}$ \\
Ala30Pro & & & & \\
$\mathrm{NaCl}$ & 53.2 & 0 & 46.8 & $40 \mathrm{Na}^{+}, 7 \mathrm{Cl}^{-}$ \\
\hline
\end{tabular}


Table Continued

\begin{tabular}{|c|c|c|c|c|}
\hline Salt & \%Helix & \%Sheet & \%Loop & Number of lons \\
\hline $\mathrm{KCl}$ & 57.9 & 0 & 42.1 & $19 \mathrm{~K}^{+}, 11 \mathrm{Cl}^{-}$ \\
\hline $\mathrm{CaCl}_{2}$ & 57.5 & 1.4 & 41.1 & $4 \mathrm{ICa}^{2+}, 5 \mathrm{Cl}^{-}$ \\
\hline $\mathrm{MgCl}_{2}$ & 53.2 & 0 & 46.8 & $37 \mathrm{Mg}^{2+}, 1 \mathrm{ICl}^{-}$ \\
\hline $\mathrm{ZnCl}_{2}$ & 51.4 & 0 & 48.6 & $0 \mathrm{Zn}^{2+}, 9 \mathrm{Cl}^{-}$ \\
\hline \multicolumn{5}{|c|}{ Truncation } \\
\hline $\mathrm{NaCl}$ & 48.6 & 0 & 51.4 & $30 \mathrm{Na}^{+}, 19 \mathrm{Cl}^{-}$ \\
\hline $\mathrm{KCl}$ & 55.9 & 0 & 44.1 & $10 \mathrm{~K}^{+}, 15 \mathrm{Cl}^{-}$ \\
\hline $\mathrm{CaCl}_{2}$ & 57.3 & 0 & 42.7 & $24 \mathrm{Ca}^{2+}, 13 \mathrm{Cl}^{-}$ \\
\hline $\mathrm{MgCl}_{2}$ & 47.7 & 0 & 52.3 & $16 \mathrm{Mg}^{2+}, 14 \mathrm{Cl}^{-}$ \\
\hline $\mathrm{ZnCl}_{2}$ & 48.2 & 0 & 51.8 & $25 \mathrm{Zn}^{2+}, 20 \mathrm{Cl}^{-}$ \\
\hline
\end{tabular}

\section{Conclusion}

In summary, the influence of metal ions $\left(\mathrm{Na}^{+}, \mathrm{K}^{+}, \mathrm{Ca}^{2+}, \mathrm{Mg}^{2+}, \mathrm{Zn}^{2+}\right)$ on the folding pathway and conformational stability of $\alpha-$ synuclein has been studied using computer simulations. In the presence of $\mathrm{Zn}^{2+}$ ions, the unfolding processes of $\alpha$-synuclein show an equal effect compared to the unfolding process of $\alpha$-synuclein in the presence of other salts. However, Shows different effect on different form of the protein dimer, in comparison to $\mathrm{Na}^{+}$, and $\mathrm{K}^{+}$which shows equal effect in maintaining the protein stability. Although the $\mathrm{Ca}^{2+}$ maintains higher stability in the wild type and truncated forms is more prone to aggregation in a mutant form of the dimer. The construction of ionbinding sites in proteins is important to the design of proteins with high thermo-stability. Therefore, the effects of metal ions on various aspects of proteins determined by the complicated interactions between the metal ions and residues deserve further study. The clinical implications of these results are important to both the design of future inhibitors of $\alpha$-synuclein oligomerization as well as for disease prevention involving metal ion effects on the brain.

\section{Acknowledgement}

I thank Prof. Maria Stepanova, Department of electrical and mechanical engineering, university of alberta, Edmonton, Canada, for providing the laboratory facilities and helpful discussions.

\section{Conflict of interest}

No potential conflict of interest was reported by the authors.

\section{References}

1. Dobson CM. Protein folding and misfolding. Nature. 2003;426(6968):884-890.

2. Ross CA, Poirier MA. Protein aggregation and neurodegenerative disease. Nature medicine. 2004;(10):10-17.

3. Lashuel HA, Labrenz SR, Woo L, et al. Protofilaments, filaments, ribbons, and fibrils from peptidomimetic self-assembly: implications for amyloid fibril formation and materials science. Journal of the American Chemical Society. 2000;122(22):5262-5277.

4. Spillantini MG, Schmidt ML, Lee VM, et al. Alpha-synuclein in Lewy bodies. Nature. 1997;388(6645):839-840.

5. Shults CW. Lewy bodies. Sciences of the United States of America.
2006;103(6):1661-1668.

6. Skovronsky DM, Lee VM, Trojanowski JQ. Neurodegenerative diseases: new concepts of pathogenesis and their therapeutic implications. Annu Rev Pathol. 2006;(1):151-170.

7. Chiti F, Dobson CM. Protein misfolding, functional amyloid, and human disease. Annu Rev Biochem. 2006;(75):333-366.

8. Eliezer D, Kutluay E, Bussell R, et al. Conformational properties of alpha-synuclein in its free and lipid-associated states. Journal of molecular biology. 2001;307(4):1061-1073.

9. Uversky VN, Li J, Fink AL. Evidence for a partially folded intermediate in alpha-synuclein fibril formation. The Journal of biological chemistry. 2001;276(14):10737-10744.

10. Uversky VN, Oldfield CJ, Dunker AK. Intrinsically disordered proteins in human diseases: introducing the $\mathrm{D}_{2}$ concept. Annu Rev Biophys. 2008;(37):215-246.

11. Dunker AK, Lawson JD, Brown CJ, et al. Intrinsically disordered protein. Journal of molecular graphics \& modelling. 2001;19(1):26-59.

12. Uversky VN. Natively unfolded proteins: a point where biology waits for physics. Protein science. 2002;11(4):739-756.

13. Uversk VN. A protein-chameleon: conformational plasticity of alphasynuclein, a disordered protein involved in neurodegenerative disorders. Journal of biomolecular structure \& dynamics. 2003;21(2):211-234.

14. Maroteaux L, Campanelli JT, Scheller RH. Synuclein: a neuronspecific protein localized to the nucleus and presynaptic nerve terminal. The Journal of neuroscience: the official. Journal of the Society for Neuroscience. 1988;8(8):2804-2815.

15. Ulmer TS, Bax A, Cole NB, et al. Structure and dynamics of micellebound human alpha-synuclein. The Journal of biological chemistry. 2005;280(10):9595-9603.

16. George JM, Jin H, Woods WS, et al. Characterization of a novel protein regulated during the critical period for song learning in the zebra finch. Neuron. 1995;15(2):361-372.

17. Davidson WS, Jonas A, Clayton DF, et al. Stabilization of alphasynuclein secondary structure upon binding to synthetic membranes. The Journal of biological chemistry. 1998;273(16):9443-9449.

18. Bussell R, Eliezer D. A structural and functional role for 11-mer repeats in alpha-synuclein and other exchangeable lipid binding proteins. Journal of molecular biology. 2003;329(4):763-778. 
19. Han H, Weinreb PH, Lansbury PT. The core Alzheimer's peptide NAC forms amyloid fibrils which seed and are seeded by beta-amyloid: is NAC a common trigger or target in neurodegenerative disease? Chemistry \& biology. 1995;2(3):163-169.

20. Ueda K, Fukushima H, Masliah E, et al. Molecular cloning of cDNA encoding an unrecognized component of amyloid in Alzheimer disease. Sciences of the United States of America. 1993;90(23):11282-11286.

21. El-Agnaf OM, Jakes R, Curran MD, et al. Effects of the mutations Ala30 to Pro and Ala53 to Thr on the physical and morphological properties of alpha-synuclein protein implicated in Parkinson's disease. FEBS letters. 1998;440(2):67-70.

22. Giasson BI, Murray IV, Trojanowski JQ, et al. A hydrophobic stretch of 12 amino acid residues in the middle of alpha-synuclein is essential for filament assembly. The Journal of biological chemistry. 2001;276(4):2380-2386.

23. Luk KC, Song C, Brien P, et al. Exogenous alpha-synuclein fibrils seed the formation of Lewy body-like intracellular inclusions in cultured cells Sciences of the United States of America. 2009;106(47):20051-20056.

24. Polymeropoulos MH, Lavedan C, Leroy E, et al. Mutation in the alphasynuclein gene identified in families with Parkinson's disease. Science. 1997;276(5321):2045-2047.

25. Zarranz JJ, Alegre J, Gomez-Esteban JC, et al. The new mutation, E46K, of alpha-synuclein causes Parkinson and Lewy body dementia. Annals of neurology. 2004;55(2):164-173.

26. Kruger R, Kuhn W, Muller T, et al. Ala30Pro mutation in the gene encoding alpha-synuclein in Parkinson's disease. Nature genetics. 1998;18(2):106-108

27. Bussell R, Eliezer D. Residual structure and dynamics in Parkinson's disease-associated mutants of alpha-synuclein. The Journal of biological chemistry. 2001;276(49):45996-6003.

28. Tsigelny IF, Bar-On P, Sharikov Y, et al. Dynamics of alpha-synuclein aggregation and inhibition of pore-like oligomer development by betasynuclein. The FEBS journal. 2007;274(7):1862-1877.

29. Mihajlovic M, Lazaridis T. Membrane-bound structure and energetics of alpha-synuclein. Proteins. 2008;70(3):761-778.

30. Yoon J, Jang S, Lee K, et al. Simulation studies on the stabilities of aggregates formed by fibril-forming segments of alpha-Synuclein. Journal of biomolecular structure \& dynamics. 2009;27(3):259-270.

31. Trexler AJ, Rhoades E. Single molecule characterization of alpha-synuclein in aggregation-prone states. Biophysical journal. 2010;99(9):3048-3055.

32. Smith WW, Schreck CF, Hashem N, et al. Molecular simulations of the fluctuating conformational dynamics of intrinsically disordered proteins. Phys Rev E Stat Nonlin Soft Matter Phys. 2012;86(4):041910.

33. Ariesandi W, Chang CF, Chen TE, et al. Temperature-dependent structural changes of Parkinson's alpha-synuclein reveal the role of pre-existing oligomers in alpha-synuclein fibrillization. Plos one. 2013;8(1):e53487.

34. Crowther RA, Jakes R, Spillantini MG, et al. Synthetic filaments assembled from C-terminally truncated alpha-synuclein. FEBS letters. 1998;436(3):309-312.

35. Serpell LC, Berriman J, Jakes R, et al. Fiber diffraction of synthetic alpha-synuclein filaments shows amyloid-like cross-beta conformation. National Academy of Sciences. 2000;97(9):4897-4902.

36. Murray IV, Giasson BI, Quinn SM, et al. Role of alpha-synuclein carboxy-terminus on fibril formation in vitro. Biochemistry. 2003;42(28):8530-8540.

37. Liu CW, Giasson BI, Lewis KA, et al. A precipitating role for truncated alpha-synuclein and the proteasome in alpha-synuclein aggregation: implications for pathogenesis of Parkinson disease. The Journal of biological chemistry. 2005;280(24):22670-22678.

38. Lewis $\mathrm{KA}, \mathrm{Su} \mathrm{Y}$, Jou $\mathrm{O}$, et al. Abnormal neurites containing $\mathrm{C}$ terminally truncated alpha-synuclein are present in Alzheimer's disease without conventional Lewy body pathology. The American journal of pathology. 2010;177(6):3037-3050.

39. Baba M, Nakajo S, Tu PH, et al. Aggregation of alpha-synuclein in Lewy bodies of sporadic Parkinson's disease and dementia with Lewy bodies. The American journal of pathology. 1998;152(4):879-884.

40. Anderson JP, Walker DE, Goldstein JM, et al. Phosphorylation of Ser-129 is the dominant pathological modification of alpha-synuclein in familial and sporadic Lewy body disease. The Journal of biological chemistry. 2006;281(40):29739-29752.

41. Gai WP, Power JH, Blumbergs PC, et al. Alpha-synuclein immunoisolation of glial inclusions from multiple system atrophy brain tissue reveals multiprotein components. Journal of neurochemistry. 1999;73(5):2093-2100.

42. Pountney DL, Voelcker NH, Gai WP. Annular alpha-synuclein oligomers are potentially toxic agents in alpha-synucleinopathy. Hypothesis. Neurotoxicity research. 2005;7(2):59-67.

43. Angelova PR, Ludtmann $\mathrm{MH}$, Horrocks $\mathrm{MH}$, et al. $\mathrm{Ca}^{2+}$ is a key factor in alpha-synuclein-induced neurotoxicity. $J$ Cell Sci 2016;129(9):1792-1801.

44. Roeters SJ, Iyer A, Pletikapic G, et al. Evidence for Intermolecular Antiparallel Beta-Sheet Structure in Alpha-Synuclein Fibrils from a Combination of Two-Dimensional Infrared Spectroscopy and Atomic Force Microscopy. Scientific reports. 2017;(7):41051.

45. Hokenson MJ, Uversky VN, Goers J, et al. Role of individual methionines in the fibrillation of methionine-oxidized alpha-synuclein. Biochemistry. 2004;43(15):4621-4633.

46. Craddock TJ, Tuszynski JA, Chopra D, et al. The zinc dyshomeostasis hypothesis of Alzheimer's disease. Plos one. 2012;7(3):e33552.

47. Sayre LM, Moreira PI, Smith MA, et al. Metal ions and oxidative protein modification in neurological disease. Ann Ist Super Sanita. 2005;41(2):143-164.

48. Kozlowski H, Swiatek J, Siatecki Z. 1H NMR studies on interactions of calcium and magnesium with aspartic acid and asparagine. Acta biochimica Polonica. 1981;28(1):1-9.

49. Binolfi A, Lamberto GR, Duran R, et al. Site-specific interactions of Cu (II) with alpha and beta-synuclein: bridging the molecular gap between metal binding and aggregation. Journal of the American Chemical Society. 2008;130(35):11801-11812.

50. Binolfi A, Rasia RM, Bertoncini $\mathrm{CW}$, et al. Interaction of alphasynuclein with divalent metal ions reveals key differences: a link between structure, binding specificity and fibrillation enhancement. Journal of the American Chemical Society. 2006;128(30):9893-9901.

51. Uversky VN, Li J, Fink AL. Metal-triggered structural transformations, aggregation, and fibrillation of human alpha-synuclein. A possible molecular NK between Parkinson's disease and heavy metal exposure. The Journal of biological chemistry. 2001;276(47):44284-44296. 